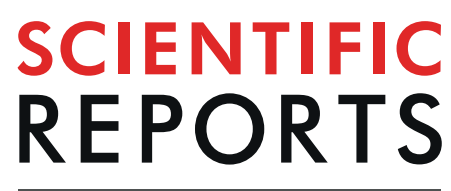

natureresearch

\title{
Metal Coated Polypropylene Separator with Enhanced Surface Wettability for High Capacity Lithium Metal Batteries
}

\begin{abstract}
Mir Mehraj Ud Din \& Ramaswamy Murugan*
Lithium metal batteries are among the strong contenders to meet the increasing energy demands of the modern world. Metallic lithium ( $\mathrm{Li}$ ) is light in weight, possesses very low standard negative electrochemical potential and offers an enhanced theoretical capacity $\left(3860 \mathrm{~mA} \mathrm{~h} \mathrm{~g}^{-1}\right)$. As a negative electrode Li paves way to explore variety of elements including oxygen, sulfur and various other complex oxides as potential positive electrodes with a promise of much higher energy densities than that of conventional positive electrodes. However, there are technical challenges in utilizing metallic lithium due to its higher reactivity towards liquid electrolytes and higher affinity to form Li dendrites, leading to serious safety concerns. Here, we report on preparation of niobium ( $\mathrm{Nb}$ ) metal-coated binderfree and highly hydrophilic polypropylene separator prepared via radio frequency (RF) magnetron sputtering. Thin layer of niobium metal (Nb) particles were deposited onto the polypropylene (PP) sheet for various time periods to achieve desired coating thickness. The as-prepared separator revealed excellent hydrophilic behaviour due to enhanced surface wettability. Symmetric cells display reduced interface resistance and uniform voltage profiles for 1000 cycles with reduced polarization at higher current densities suggesting smooth stripping and plating of $\mathrm{Li}$ and homogeneous current distribution at electrode/electrolyte interface under room temperature conditions. $\mathrm{Nb}$ nanolayer protected separator with $\mathrm{LiNi}_{0.33} \mathrm{M}_{0.33} \mathrm{Co}_{0.33} \mathrm{O}_{2}$ (LNMC) and composite sulfur cathodes revealed an enhanced cycling stability.
\end{abstract}

Current research in lithium ion batteries (LiBs) is mainly focused on utilization of metallic lithium (Li) as anode material for developing advanced high energy density lithium metal batteries based on conventional insertion-type cathodes and several other high capacity cathode materials. $\mathrm{LiCoO}_{2}$ is widely used as cathode material in LiBs due to its reasonable cycling stability ${ }^{1-6}$. However, higher cost, toxicity and lower practical capacity limits its applications ${ }^{7,8}$. To fulfil the requirement for cathode materials with relatively enhanced properties, an insertion-type cathode of $\mathrm{LiNi}_{1 / 3} \mathrm{Mn}_{1 / 3} \mathrm{Co}_{1 / 3} \mathrm{O}_{2}$ composition containing mixed metal ions with relatively higher reversible capacity and better thermal stability is reported for $\mathrm{LiBs}^{6}$. It exhibits the similar crystal structure as that of $\mathrm{LiCoO}_{2}$ (rhombohedral, $R 3 m$ symmetry, with $\mathrm{MO}_{6}$ octahedral sharing the edges ("M" $=\mathrm{Co}, \mathrm{Ni}$, and $\mathrm{Mn}$ ) and $\mathrm{Li}$ ions $\left(\mathrm{Li}^{+}\right)$in the structure occupy the respective octahedral sites. $)^{9,10}$. Ni, Mn, and Co ions exist with valances of $+2,+4$, and +3 , respectively and the $\mathrm{Ni}^{2+} / \mathrm{Ni}^{4+}$ and $\mathrm{Co}^{3+} / \mathrm{Co}^{4+}$ redox couples are electrochemically active during the insertion/removal of $\mathrm{Li}^{+}$, whilst the $\mathrm{Mn}^{4+}$ ions remain inactive ${ }^{11-15}$. As a consequence, the Mn dissolution and associated Jahn-Teller distortion can be greatly eluded, which in turn results in a more stabilized structure during the electrochemical processes ${ }^{10,16}$. The $\mathrm{LiNi}_{1 / 3} \mathrm{Mn}_{1 / 3} \mathrm{Co}_{1 / 3} \mathrm{O}_{2}$ cathode offers a practical achievable specific capacity of above $160 \mathrm{~mA} \mathrm{~h} \mathrm{~g}^{-1}$ when cycled in $2.5 \mathrm{~V}$ to $4.5 \mathrm{~V}$ voltage range. This capacity is relatively higher than the $\mathrm{LiCoO}_{2}$ (cycled in $3 \mathrm{~V}$ to $4.3 \mathrm{~V}$ voltage range). Another cathode material investigated for high capacity $\mathrm{LiBs}$ is sulfur. Lithium-sulfur batteries ( $\mathrm{Li}-\mathrm{S}$ ) are considered as promising for vehicle electrification due to their much higher theoretical specific capacities and energy densities than conventional LiBs. Sulfur is abundantly available in reserves which renders it cost effective and higher electrochemical activity makes it suitable candidate to fit-in as a cathode material for Li-S batteries. However the practical comprehension is still lacking due to various technical challenges, which are more critical than other $\mathrm{Li}^{+}$battery systems. Sulfur although possesses 
excellent electrochemical activity, the poor electrical conductivity $\left(5 \times 10^{-31} \mathrm{~S} \mathrm{~cm}^{-1}\right)$ limits its direct utilization as a positive electrode for practical application ${ }^{17-22}$. To overcome this challenge, sulfur is usually bonded with different conducting hosts by physical adhesion or chemical interactions to provide the missing conductivity to sulfur $^{23-33}$. Second drawback of sulfur utilization is the volume expansion due to series of reactions taking place in $\mathrm{Li}-\mathrm{S}$ cell during electrochemical process, giving rise to the formation of intermediate products commonly known as Li polysulfide ${ }^{34-39}$. The octa-sulfur $\left(\mathrm{S}_{8}\right)$, an allotrope of elemental sulfur reduces into higher-chain poly-sulfur species $\left(\mathrm{Li}_{2} \mathrm{~S}_{x}, 6 \leq x \leq 8\right)$ on reaction with $\mathrm{Li}^{+}$during discharge process ${ }^{21}$. These higher-chain reaction products are soluble in liquid medium and upon dissolution diffuse through the porous separator and reach at the anode region, where they further reduced into lower-chain poly-sulfur species $\left(\mathrm{Li}_{2} \mathrm{~S}_{\mathrm{x}}, 1 \leq x \leq 2\right)$ on reacting with excess Li metal. The to-and-fro shuttling of these intermediate reaction products between the electrodes and inimical reactions taking place at the Li metal anode adversely affect the Li metal surface and result in higher cell resistance, reversible capacity loss and the safety concerns associated with Li dendrite formation and dendrite penetration through separator.

Metallic Li as an anode has been extensively explored for developing the high capacity Li metal batteries due to its exceptionally high theoretical capacity, lower electrochemical potential and light weight ${ }^{40}$. Unlike conventional $\mathrm{Li}$-ion batteries where carbon-based anodes are utilized, which involve the intercalation and removal of $\mathrm{Li}$ ions, lithium metal batteries containing Li metal anode involve the direct stripping and plating of $\mathrm{Li}$ at the surface of Li metal anode during electrochemical process. The continuous stripping and deposition of Li with extended cycling results in a sphere-like roots of $\mathrm{Li}^{+}$which gives rise to rough surface of Li metal anode and a severe volume change ${ }^{41-44}$. The highly rough surface of Li metal anode in turn results in nonhomogeneous current distribution on the Li nuclei. Gradually, the Li grows in a dendrite on the nuclei and ultimately, these dendrites penetrate through the separator and result in short-circuiting and thermal runaway ${ }^{45-49}$. The affinity of Li to form dendrites with extended cell cycling is highly hazardous and leads to safety concerns in such type of cell. Separators in batteries play a crucial role in regulating the movement of electrolyte matrix containing the mixed ions. Conventionally used polypropylene separators are porous in nature and as-such allow the dendrite penetration and smooth movement of reaction intermediates to travel across the electrodes with extended cell cycling ${ }^{50}$. Extensive research has been devoted towards designing the efficient membrane separators to shield the $\mathrm{Li}$ anode and also to anchor the diffusion of polysulfides in Li-S batteries. Various conductive coating materials such as carbon coatings ${ }^{20}$, polymeric coatings ${ }^{51}$, ceramic coatings ${ }^{52,53}$, on separator surface are reported to effectively restrict the polysulfide diffusion during cell cycling. However, these coatings are generally applied on the cathode regions and involve the conventional preparation technique such as slurry casting process which results in higher coating thickness, thus negatively impacting the cell impedance and cell performance due to presence of polymeric binders in the slurry and allowing the Li dendrite penetration due to unprotected Li metal anode. It is therefore essential to address the critical issues associated with the Li metal utilization in Li-S batterers. Magnetron sputtering technique has been highly effective in achieving uniform coating layers of metals/non-metal and their oxides such as $\mathrm{Al}, \mathrm{Cu}, \mathrm{Nb}, \mathrm{Pt}, \mathrm{Al}_{2} \mathrm{O}_{3}, \mathrm{LiNb}_{2} \mathrm{O}_{3}$ etc., with controlled coating thickness ${ }^{54-59}$. Various metallic nanolayer coatings on to the separator membranes have been reported for mitigation of polysulfide diffusion ${ }^{60}$, as well as supressing the Li dendrite penetration ${ }^{54,58}$. Niobium metal and its oxides possess excellent electrical and mechanical properties and are reported to improve the performance of LiBs and mitigate the serious issues related to polysulfide diffusion in Li-S batteries ${ }^{61-63}$. Recent reports revealed that the oxides of $\mathrm{Nb}$ such as $\mathrm{Nb}_{2} \mathrm{O}_{5}$ show strong affinity towards Li polysulfide thereby preventing their dissolution during electrochemical process and effectively improve the battery performance. Herein, we report the niobium metal deposited PP separator prepared via RF magnetron sputtering. High mechanical strength of the $\mathrm{Nb}$ coating is advantageous in supporting the structural integrity of $\mathrm{Li}$ during the electrochemical process. We demonstrate that this technique can suppress the dendrite penetration by dendrite merging, which is essential for achieving the improved contact and uniform charge distribution at the electrode-electrolyte interface. The nanolayer of $\mathrm{Nb}$ metal deposited on one side of the PP separator serves as an additional conducting agent to facilitate electrochemical stripping/deposition of Li metal with relatively very less accumulation of electrically isolated or "dead" Li. Furthermore, the electrically conductive nature of $\mathrm{Nb}$ coating guides the deposition of $\mathrm{Li}$ metal and controls the Li deposition morphology. The uncoated surface of $\mathrm{Nb}$-PP facing the cathode, serves as an insulating substrate while the conductive side of the $\mathrm{Nb}-\mathrm{PP}$ separator is in contact with $\mathrm{Li}$ anode. The Li symmetric cell with Li||Nb-PP@Nb-PP||Li configuration and $\mathrm{Li}|| \mathrm{Nb}-\mathrm{PP}|| \mathrm{LNMC}$ and Li || $\mathrm{Nb}-\mathrm{PP}|| \mathrm{S}$ cells assembled with modified separator membrane display improved stability and better electrochemical performances.

\section{Results and Discussion}

Microstructure and wettability of PP separator and Nb-PP separator. The microstructure of PP separator and $\mathrm{Nb}-\mathrm{PP}$ separator was studied via scanning electron microscope. Figure 1 displays the SEM micrographs of PP and Nb-PP (with optimized coating thickness of $\sim 60 \mathrm{~nm}$ ) separators. The SEM images of pristine PP separator display a highly porous and $\mathrm{Nb}$-free surface (Fig. 1a,b). The cross-sectional SEM image of PP separator shows that the thickness of PP was $24.7 \mu \mathrm{m}$ (Fig. 1c). EDS image and the elemental map confirms the Nb-free surface of porous PP separator (Fig. 1d,e). In contrast, Nb-PP separator displays a uniform and thin deposition of $\mathrm{Nb}$ metal particles covering the porous surface of PP separator (Fig. 1f,g). The cross-sectional SEM images of $\mathrm{Nb}$ coated $\mathrm{PP}$ separator (Fig. $\mathrm{lh}$ ) reveals the average $\mathrm{Nb}$ coating thickness of $60 \mathrm{~nm}$. EDS image and the elemental maps suggest the homogeneous distribution of Nb deposition onto the PP separator surface (Fig. 1h-k). The EDS data of uncoated surface of Nb-PP separator is presented in Fig. S1. The lightly dense coating on PP separator surface could help in improving the surface wettability towards the liquid electrolyte and protect the separator from $\mathrm{Li}$ dendrite penetration, without blocking the channels for $\mathrm{Li}^{+}$transport ${ }^{56,59}$, whilst retaining the good thermal stability. Insets in Fig. 1a,f are the digital photographs of uncoated and Nb coated surfaces of Nb-PP separator. The thermal stability of separators was investigated via DSC and is presented in the Supplementary Information 

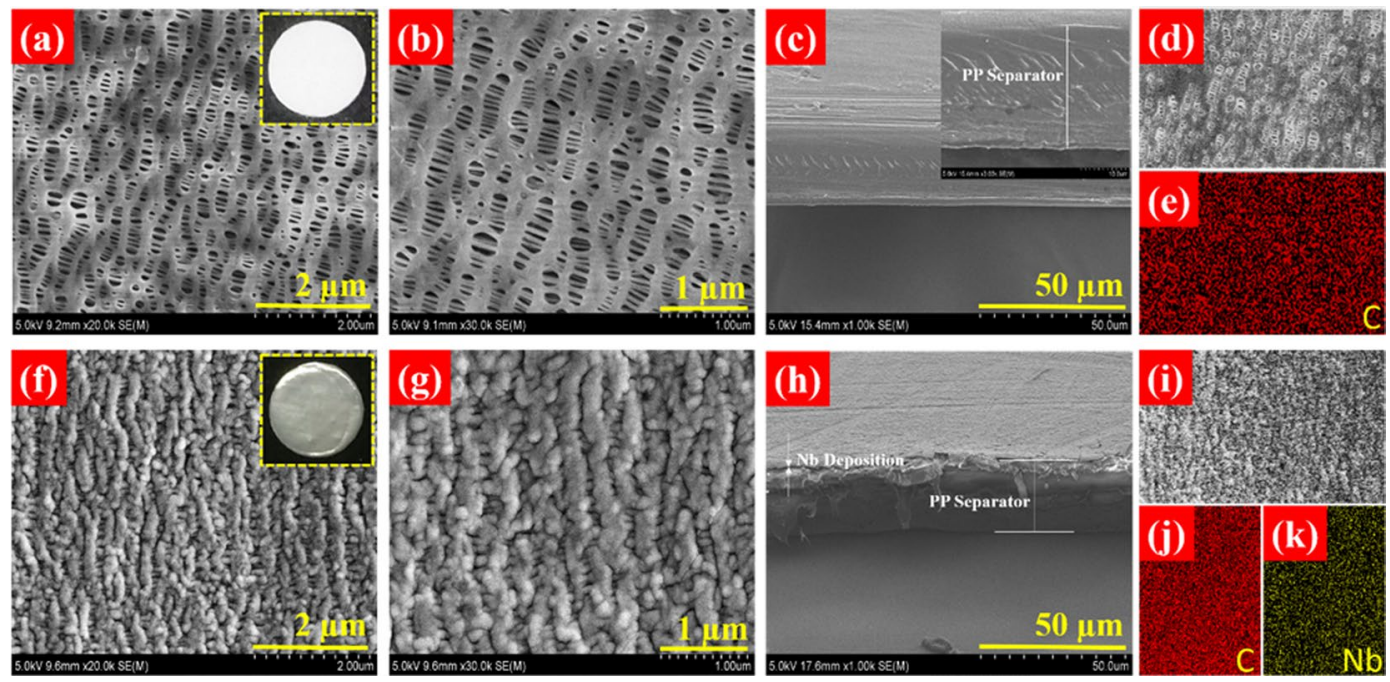

Figure 1. (a,b) HRSEM images of pristine PP separator and (c) it's cross-sectional view. (d,e) EDS image and elemental map of PP separator. (f,g) HRSEM images of Nb-PP separator and (h) it's cross-sectional view. (i) EDS image and $(\mathbf{j}, \mathbf{k})$ elemental maps of Nb-PP separator. Insets in $(\mathbf{a}, \mathbf{f})$ are the digital photographs of pristine surface and $\mathrm{Nb}$ coated surface of PP separator.

(Fig. S2). For comparison of morphologies of samples, other deposition times were also considered (Fig. S3). For the deposition time of $15 \mathrm{~min}$ (Fig. S3a) the coating looks thin with notable porous surface which, in turn could result in homogeneous current distribution at the interface during electrochemical cycling process without impairing the ion transport ${ }^{56}$. For the $30 \mathrm{~min}$ (Fig. S3b) deposition time, the surface of separator looks very much flat which may improve the interface contact with $\mathrm{Li}$ electrodes but the thick coating may block the $\mathrm{Li}^{+}$during electrochemical process. For the deposition time of $60 \mathrm{~min}$ (Fig. S3c), the coating is more obvious and is likely to be fracted onto the PP separator, which could result in uneven Li deposition during galvanostatic cycling pro$\operatorname{cess}^{55,60}$. Thus, the sputtering time of $15 \mathrm{~min}$ was preferred. The $\mathrm{Nb}$ coating on PP separator is expected to assist uniform Li nucleation.

The wettability tests on $\mathrm{Nb}$ coated separator were performed via contact angle measurement method with both water and the liquid electrolyte (1.0 M L $\mathrm{M}^{-1}$ LiTFSI in DME: DOL), respectively. The amount of water and liquid electrolyte utilized for each test was $2 \mu \mathrm{L}$. The Nb-PP separator displays a relatively higher wettability towards water and the liquid electrolyte in comparison with the PP separator (Fig. S4). The Nb-PP separator exhibited a contact angle of $70.375^{\circ}$ and just $19.25^{\circ}$ with water and liquid electrolyte, respectively, while as the PP separator exhibited slightly higher contact angles of $107.09^{\circ}$ and $35.56^{\circ}$ with water and liquid electrolyte, respectively. The improved wettability of $\mathrm{Nb}$ coated separator could help in higher electrolyte uptake which, in turn may result in improved electrochemical performance of a cell.

Electrochemical testing of symmetric cells. The schematic illustration of symmetric cell components and the Li stripping/deposition during electrochemical cycling based on PP separator and the Nb-PP separator is presented in Fig. 2(a-f). The electrical property of pristine surface and $\mathrm{Nb}$ coated surface of Nb-PP separator was investigated. The uncoated surface of $\mathrm{Nb}-\mathrm{PP}$ separator was non-conducting when tested with ohmic-meter, indicating no diffusion of $\mathrm{Nb}$ coating during sputtering process (Fig. S5a). The $\mathrm{Nb}$ coated surface of $\mathrm{Nb}-\mathrm{PP}$ separator shows surface resistance indicating its conductive nature (Fig. S5b), while as the uncoated surface of Nb-PP separator exhibits highly insulating properties. Galvanostatic cycling was carried out at different current densities in symmetrical Li cell with Li||Nb-PP@PP-Nb||Li configuration to investigate the Li deposition process in this system (Fig. 3). The cycle duration was $30 \mathrm{~min}$ and the total time for which the cycling was performed was $500 \mathrm{~h}$. The Li||Nb-PP@PP-Nb||Li symmetric cell exhibited a noise-free voltage profile throughout cycling, suggesting a homogeneous current distribution at the Li metal surface. The symmetric cell exhibited the stable over potential of approximately $0.03 \mathrm{~V}$ at $0.1 \mathrm{~mA} \mathrm{~cm}^{-2}, 0.2 \mathrm{~mA} \mathrm{~cm}^{-2}$, and $0.25 \mathrm{~mA} \mathrm{~cm}^{-2}$, respectively, corresponding to each $\mathrm{Li}|| \mathrm{Nb}-\mathrm{PP}$ interface area specific resistance of nearly $30 \Omega \mathrm{cm}^{2}$. When cycled at $0.5 \mathrm{~mA} \mathrm{~cm}^{-2}$, the Li||Nb-PP@ $\mathrm{PP}-\mathrm{Nb} \| \mathrm{Li}$ symmetric cell displayed a relatively lower polarization of $0.04 \mathrm{~V}$ with smooth $\mathrm{Li}$ stripping and deposition profiles in comparison to Li ||PP@PP |Li symmetric cell with huge polarization and erratic Li stripping and plating profile at $0.5 \mathrm{~mA} \mathrm{~cm}^{-2}$ (Fig. 4a). The enlarged voltage profiles of the respective cycles corresponding to Li||PP@PP||Li and Li||Nb-PP@PP-Nb||Li symmetric cells are presented in Fig. 4(b-d). The higher polarization in the Li||PP@PP||Li cell could be associated with the inhomogeneous current distribution at the Li||PP interface because of non-uniform Li deposition on PP separator surface ${ }^{58}$. EIS measurements (Fig. S6) were performed for the symmetric cells to confirm the effect of $\mathrm{Nb}$ nanolayer in improving the interface contact. The symmetric cell with PP separator displayed an interface resistance of $125.5 \Omega$ before cycling and an increased contact resistance of $208.2 \Omega$ after cycling (Fig. S6b). The Nb-PP symmetric cell on the other hand, exhibited an interface resistance of $134.5 \Omega$ before cycling and much lower resistance of just $13.8 \Omega$ after cycling (Fig. S6c). Improved interface 

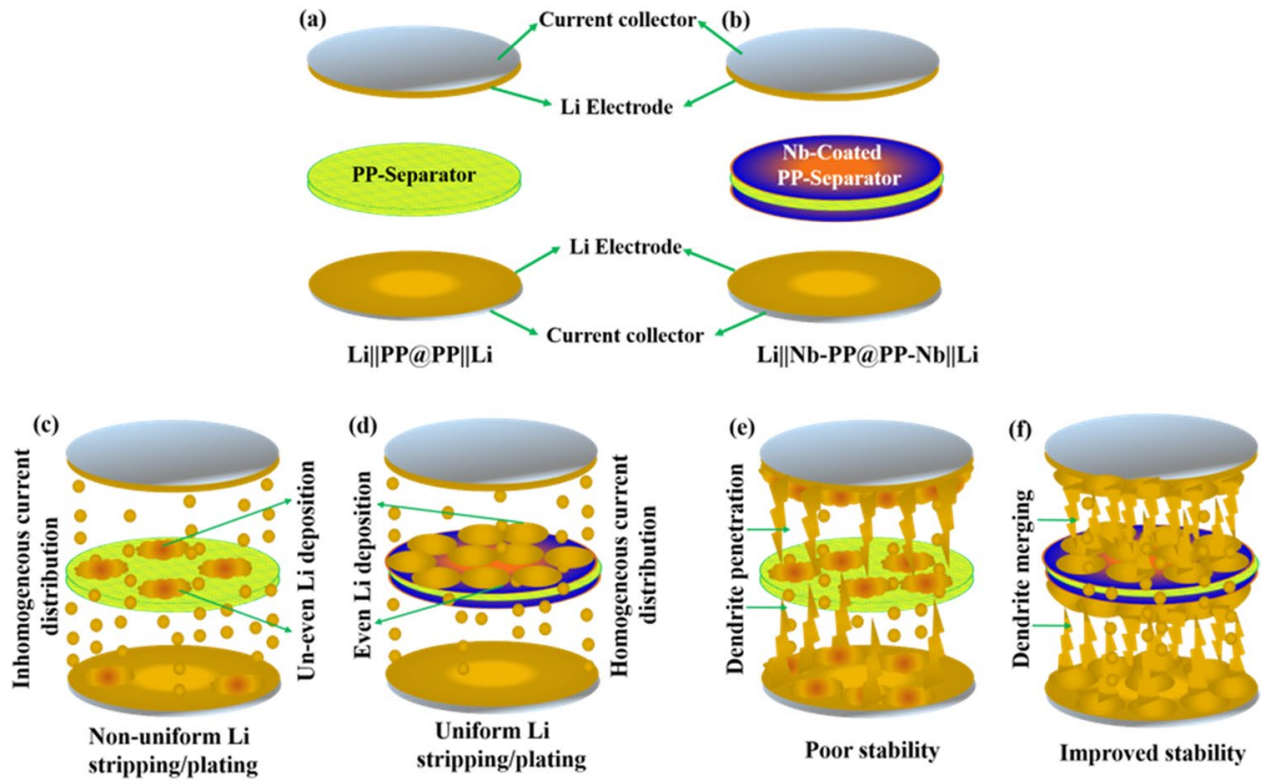

Figure 2. Schematic representation of (a) Li||PP@PP||Li symmetric cell and (b) Li||Nb-PP@PP-Nb||Li symmetric cell components assembled in Swagelok. (c,d) Schematic of Li||PP@PP||Li symmetric cell cycling showing uneven and even lithium deposition on to the separators surface. (e,f) Schematic demonstration of lithium dendrite penetration in Li||PP@PP ||Li symmetric cell and lithium dendrite merging in Li||Nb-PP@PP$\mathrm{Nb} \|$ Li symmetric cell.
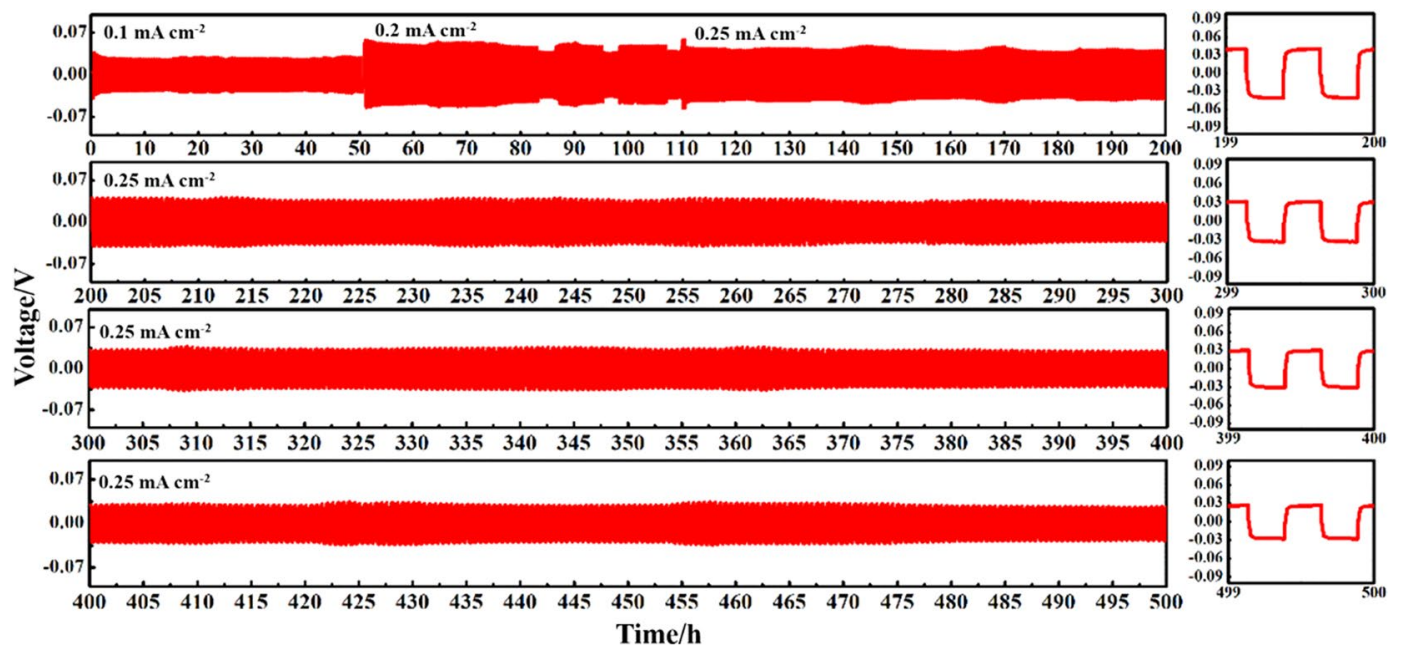

Figure 3. Time dependent voltage profiles of Li||Nb-PP@PP-Nb||Li symmetric cell for $500 \mathrm{~h}$ at different current densities reflecting a uniform stripping and deposition of lithium. Plots on the right side present the enlarged view of voltage profiles for the respective cycles.

contact could be the possible reason for reduction in the contact resistance in the latter case. To further confirm the stability of $\mathrm{Nb}-\mathrm{PP}$ separator a rate performance test for the $\mathrm{Li}|| \mathrm{Nb}-\mathrm{PP} @ \mathrm{PP}-\mathrm{Nb} \| \mathrm{Li}$ symmetric cell was performed at current densities $0.2 \mathrm{~mA} \mathrm{~cm}^{-2}, 0.4 \mathrm{~mA} \mathrm{~cm}^{-2}, 0.6 \mathrm{~mA} \mathrm{~cm}^{-2}, 0.8 \mathrm{~mA} \mathrm{~cm}^{-2}$ and $1 \mathrm{~mA} \mathrm{~cm}^{-2}$, respectively, as depicted in Fig. S7a. The cell exhibited a stable voltage profile at each current density, indicating a uniform current distribution at the interface. EIS tests were performed after every 50 cycles at each current density, reflecting the reduction in interface resistance (Fig. S7b). The $\mathrm{R}_{1}$ (electrolyte resistance) values of the cell showed stable area specific resistance of nearly $5.4 \Omega \mathrm{cm}^{2}$ before and after cycling for $100 \mathrm{~h}$ at $0.2 \mathrm{~mA} \mathrm{~cm}^{-2}$ and $0.8 \mathrm{~mA} \mathrm{~cm}^{-2}$, respectively (see inset in Fig. S7b and Table S1). The relatively stable and lower values of $\mathrm{R}_{1}$ and the interface resistance with galvanostatic cycling indicates that the bi-directional growth of $\mathrm{Li}$ from the anode surface and the $\mathrm{Nb}$ surface could have result in higher stability of the electrode/electrolyte interface ${ }^{58}$. Post-mortem analysis of symmetric cells with PP and Nb-PP separators was performed to investigate the cycled separators and the Li metal surface. The Swagelok-type cells were dissembled inside glove box. The recovered separator and the Li discs were carefully washed with DME to remove the deposited reaction products on the surface and left for drying in glove box. The 

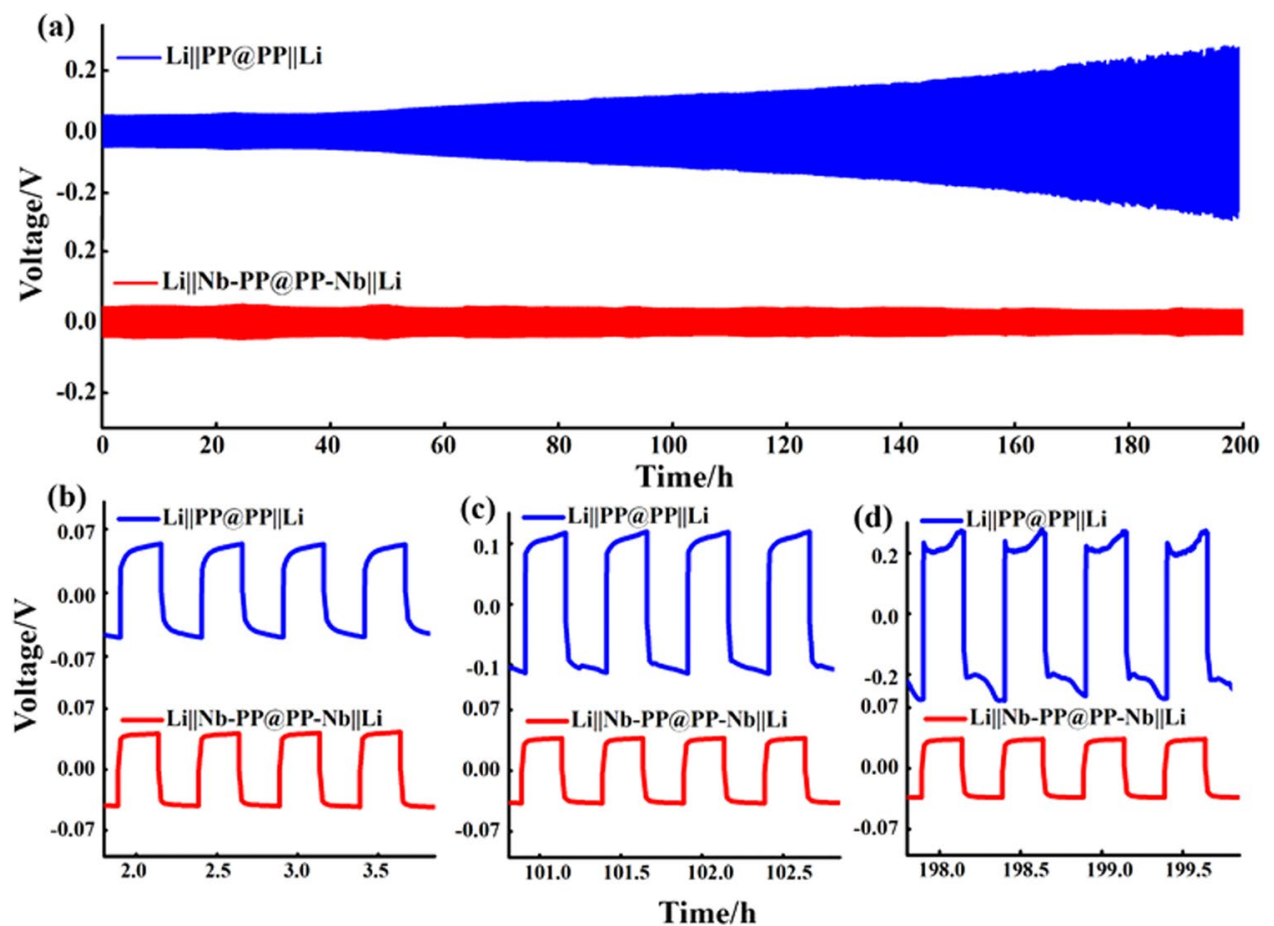

Figure 4. (a) Time dependent voltage profiles of Li||PP@PP||Li and Li||Nb-PP@PP-Nb||Li symmetric cells at a current density of $0.5 \mathrm{~mA} \mathrm{~cm}^{-2}$. (b-d) Enlarged voltage profiles of Li||PP@PP ||Li and Li || $\mathrm{Nb}-\mathrm{PP} @ \mathrm{PP}-\mathrm{Nb}|| \mathrm{Li}$ symmetric cells for the respective time periods.
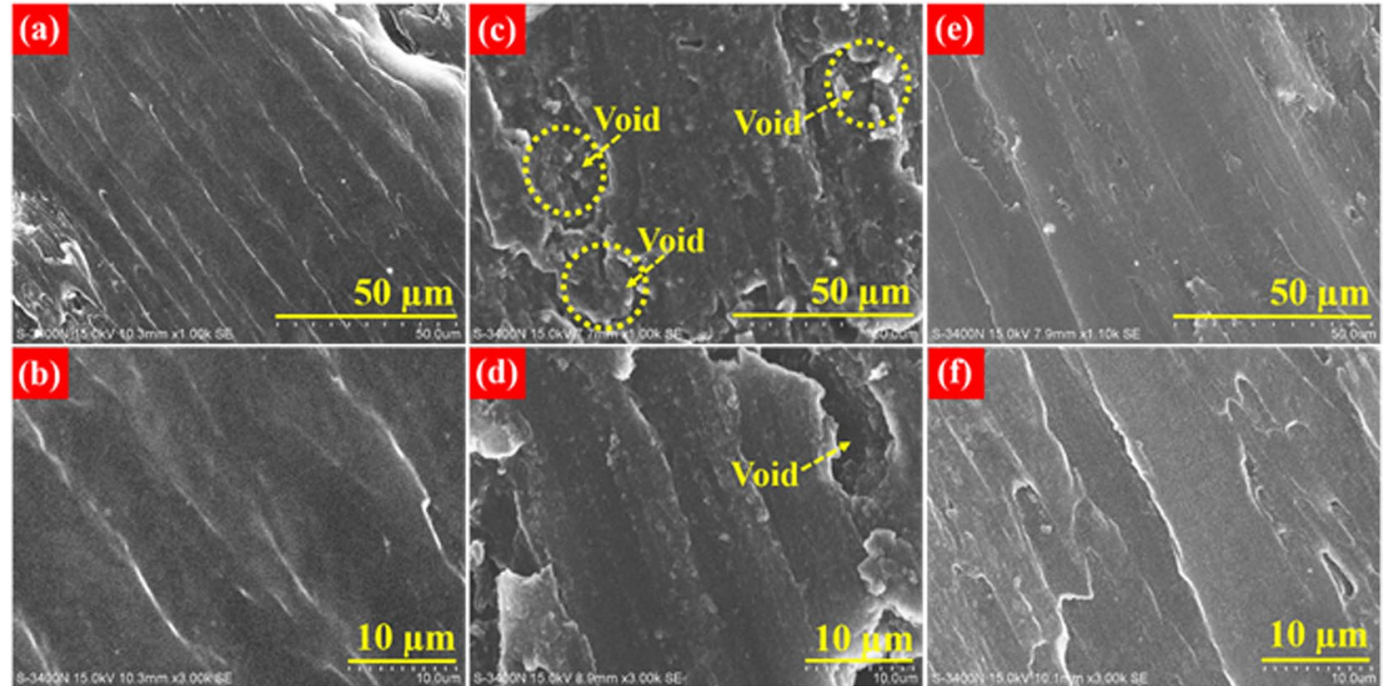

Figure 5. (a) SEM image of pristine Li foil revealing a smooth surface. (b) SEM image of pristine Li foil at higher magnification. (c) SEM image of washed Li foil after cycling with pristine PP separator displaying a rough surface due to inhomogeneous lithium extraction/deposition during galvanostatic cycling. (d) It's magnified view. (e) SEM image of washed Li foil after cycling with $\mathrm{Nb}$-PP separator reflecting a relatively smooth surface. (f) It's magnified view.

dried separators and the Li discs were carefully sealed in vacuum boxes for microstructural analysis. The pristine Li displays a smooth surface as depicted in Fig. 5(a,b). The Li surface cycled in pristine PP separator containing symmetric cell exhibits a rough surface with large number of voids created due to inhomogeneous stripping and platting of Li which could have results in non-uniform current distribution at the electrode interface (Fig. 5c,d). The Li surface cycled in Nb-PP separator containing symmetric cell on the other hand exhibited a relatively smoother surface without the presence of any visible voids (Fig. 5e,f). The improved stability behaviour of Li surface could be ascribed to bi-directional growth of $\mathrm{Li}$ on anode and $\mathrm{Nb}$ surface, resulting in homogenous stripping and platting of Li during galvanostatic cycling ${ }^{46,56,58,64}$. The Li deposited on the surface of Li anode 

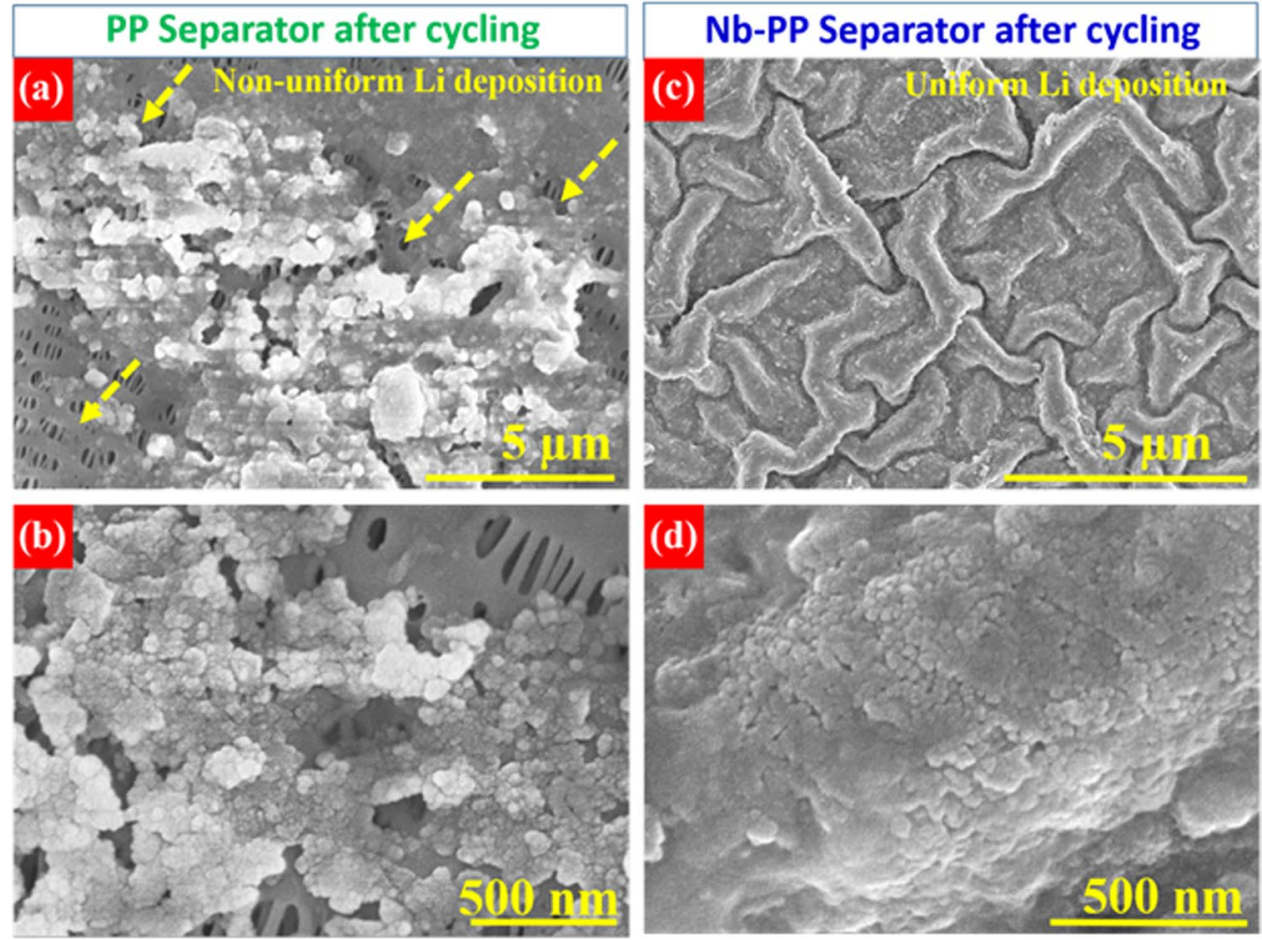

Figure 6. HR-SEM image of (a) pristine PP separator surface after cycling (b) It's magnified view. HR SEM image of (c) Nb-PP separator surface after cycling and (d) It's magnified view displaying uniform deposition of lithium on the surface of separator.

grows towards the $\mathrm{Nb}$ surface of PP separator and the Li deposited on Nb-PP surface of PP separator grows towards the Li anode. The grown Li from two ends merge together and results in not only the uniform current distribution but also prevents the Li dendrites to cross the PP separator which otherwise could result in thermal runaway due to short circuiting ${ }^{56}$. Besides, the HRSEM analysis of cycled PP separator and the Nb-PP separator was performed to investigate the nature of deposition of Li onto the separators surface. The PP separator surface displayed an un-even deposition of Li (Fig. 6a,b), which could have resulted in the non-uniform current distribution and finally the increased polarization voltage in the symmetric cell with Li||PP@PP ||Li configuration. The SEM images of cycled separators and Li surface displaying the morphology of lithium deposition are presented in Figs. S8 and S9, respectively. EDS image of cycled PP separator and the associated elemental maps are presented in Fig. S10 in the supplementary information. HRSEM images of cycled Nb-PP separator on the other hand display highly uniform deposition of Li on the separator surface (Fig. 6c,d), which in turn could have resulted in the homogeneous current distribution across the interface and hence the stable polarization voltage. EDS image of cycled $\mathrm{Nb}$-PP separator further confirm the uniform deposition and stripping of Li metal responsible for homogeneous current distribution across the interface (Fig. S11). The above result confirms the effect of Nb coating layer in improving the electrochemical stability of the Li symmetric cell and is in well, agreement with the reported literature ${ }^{56,58}$.

Electrochemical performance evaluation of half cells containing LNMC cathode and composite sulfur cathode. To investigate the effectiveness of $\mathrm{Nb}$ nanolayer deposition on cell performance, cells with LNMC and composite sulfur cathodes were constructed. CV measurements were performed for the LNMC cathode based cells in $2.5 \mathrm{~V}$ to $4.5 \mathrm{~V}$ voltage range at $0.1 \mathrm{mVs}^{-1}$. Cells containing $\mathrm{PP}$ and $\mathrm{Nb}-\mathrm{PP}$ separators show a pair of redox peaks corresponding to the $\mathrm{Ni}^{2+} / \mathrm{Ni}^{4+}$ during the $\mathrm{Li}^{+}$insertion and removal ${ }^{16}$. The redox peaks for the first CV scan are centered at $4.16 \mathrm{~V}$ and $3.65 \mathrm{~V}$ respectively, resulting in a potential difference of $0.51 \mathrm{~V}$ (Fig. S12). The potential difference shows a dip after successive scans and attained a minimum value of $0.17 \mathrm{~V}$ for the $10^{\text {th }}$ CV scan attaining a peak current of magnitude $0.10 \mathrm{~mA}$. The Nb-PP separator based cell on the other hand, displayed the potential difference of only $0.15 \mathrm{~V}$ corresponding to the redox peaks at $4.14 \mathrm{~V}$ and $3.63 \mathrm{~V}$ for the first $\mathrm{CV}$ scan with reduced potential difference value of $0.19 \mathrm{~V}$ and higher peak current of magnitude $0.13 \mathrm{~mA}$. The exceptionally low potential difference indicates the better cycling reversibility ${ }^{16}$. The relatively higher peak current in the latter case could be associated with the improved electrical contact between $\mathrm{Nb}$ and Li metal anode which may promote fast $\mathrm{Li}^{+}$transport across the anode|electrolyte interface ${ }^{65}$. These results are in accordance with the Randles-Sevcik equation, where peak current $\left(\mathrm{I}_{\mathrm{p}}\right)$ is proportional to the square root of diffusion coefficient $\left(\mathrm{D}_{\mathrm{Li}}{ }^{+}\right)$ of $\mathrm{Li}^{+}$. Furthermore no reduction peak near $3.0 \mathrm{~V}$ was observed in the $\mathrm{CV}$ curves and it can be concluded that $\mathrm{Mn}$ retained its +4 oxidation status in the structure. The $\mathrm{Mn}^{4+}$ ions are inactive within the LNMC lattice, as a consequence it results in stabilizing the lattice. In the CV cycle a homologous integral area was observed, suggesting that the Li intercalation and intercalation was highly reversible ${ }^{10}$. Figure $7(\mathrm{a}, \mathrm{b})$ show the charge-discharge curves 

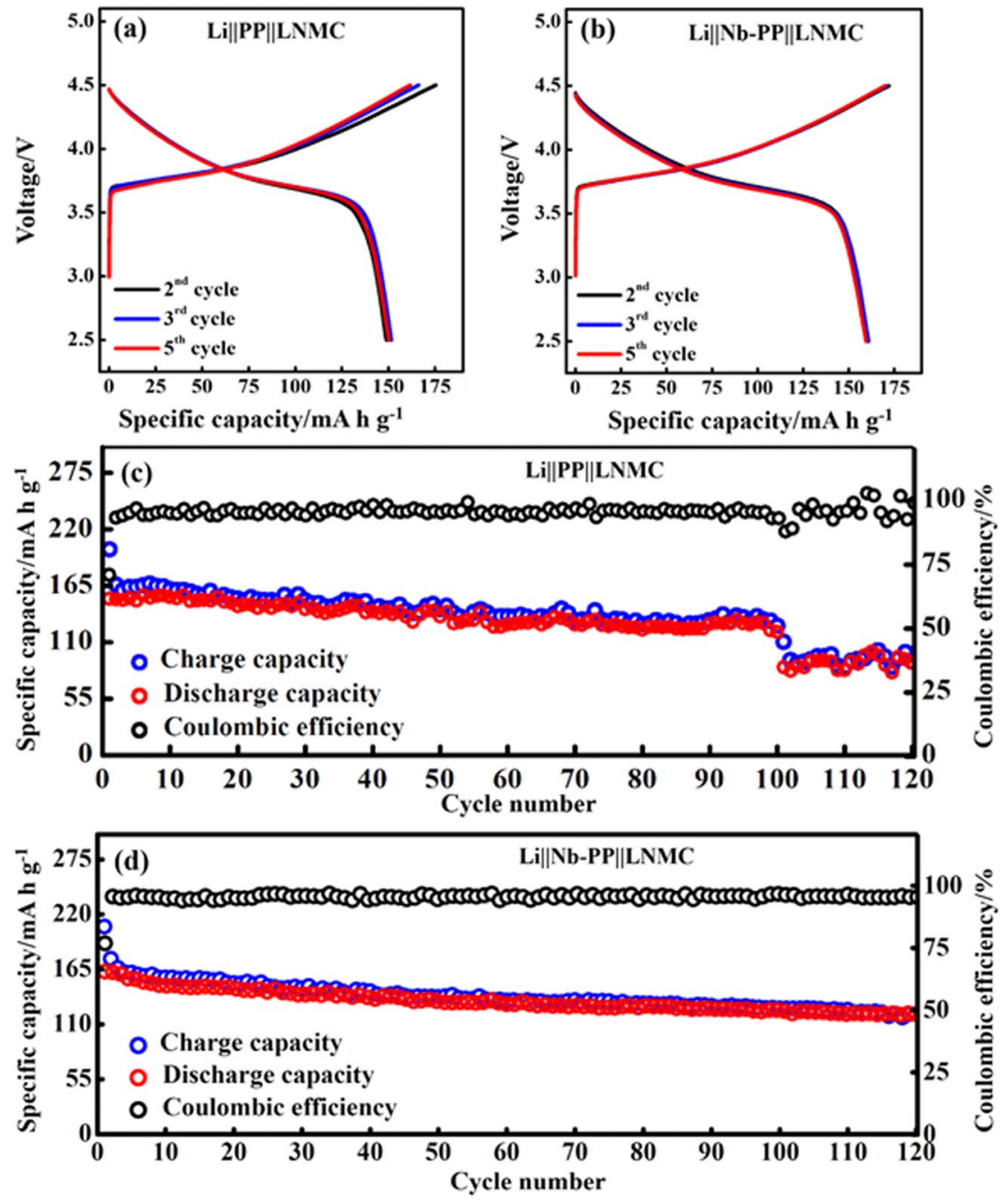

Figure 7. (a) Voltage profiles of LNMC cathode cell with PP separator. (b) Voltage profiles of LNMC cathode cell with Nb-PP separator. (c) Charge-discharge capacity and Coulombic efficiency of LNMC cathode PP separator. (d) Charge-discharge capacity and Coulombic efficiency of LNMC cathode with Nb-PP separator showing improved cycling stability.

of LNMC cells without and with $\mathrm{Nb}$-PP separator in a stable voltage range of $2.5 \mathrm{~V}$ to $4.5 \mathrm{~V}$. The corresponding specific capacities and efficiencies with cycle number are presented in Fig. 7(c,d). The PP separator based LNMC cell delivered an initial discharge capacity of $150 \mathrm{~mA} \mathrm{~h} \mathrm{~g}^{-1}$ and a discharge capacity of $90 \mathrm{~mA} \mathrm{~h} \mathrm{~g}^{-1}$ after 120 cycles at $0.2 \mathrm{C}\left(1 \mathrm{C}=180 \mathrm{~mA} \mathrm{~h} \mathrm{~g}^{-1}\right)$ with Coulombic efficiency of below $95 \%$. In contrast, the charge-discharge curves corresponding to $\mathrm{Nb}-\mathrm{PP}$ show better reversibility with an initial discharge capacity of $165 \mathrm{~mA} \mathrm{~h}^{-1}$ at $0.2 \mathrm{C}$. The cell exhibited reasonable reversible capacity of $130 \mathrm{~mA} \mathrm{~h}^{-1}$ for the $120^{\text {th }}$ discharge with an efficiency of above $97 \%$. The relatively better cycling performance of LMNC cell with Nb-PP separator could be ascribed to the improved $\mathrm{Li}^{+}$diffusion at the electrode electrolyte interface and better stability of Li metal anode during electrochemical process. The above results suggest that the $\mathrm{Nb}$ coating on PP separator not only allows enhanced $\mathrm{Li}^{+}$ transport but also acts as a buffer for the Li dendrites growth and penetration.

As mentioned earlier, the exceptionally higher theoretical capacity of sulfur makes it an ideal material for Li metal batteries with higher energy densities. Li-S cells were constructed to demonstrate the effect of Nb coating on supressing the Li dendrite penetration and the polysulfide anchoring. The CV test in $1.7 \mathrm{~V}$ to $2.8 \mathrm{~V}$ voltage range at $0.1 \mathrm{mV} \mathrm{s}^{-1}$, was conducted for the Li-S cells containing pristine PP and Nb-PP separators (Fig. S13a,b). Two reduction peaks were observed in the cathodic scan at around the potential of $2.25 \mathrm{~V}$ and $2.01 \mathrm{~V}$ corresponding to the reduction of sulfur to long-chain polysulfides $\left(\mathrm{Li}_{2} \mathrm{~S}_{\mathrm{n}} ; 4 \leq n \leq 8\right)$ and at $2.0 \mathrm{~V}$ corresponding to the further reduction of long-chain Li polysulfide into insoluble short- chain Li polysulfides. In the anodic scan, two oxidation peaks observed at $2.34 \mathrm{~V}$ and $2.39 \mathrm{~V}$ are associated with the conversion of lower order Li polysulfides back to elemental sulfur ${ }^{66-68}$. For the Li-S cell with PP separator, the CV curves at higher potential (2.5 V to $2.75 \mathrm{~V}$ ) in the anodic region look very much noisy with small humps (see inset in Fig. S13a) which could be associated with the possible Li polysulfide diffusion. Also the area under CV curves decreases with successive CV scans, indicating sluggish conversion kinetics and the capacity fade due to poor reaction reversibility ${ }^{69,70}$. Li-S cell with Nb-PP separator exhibited stable and smooth CV curves in the higher potential (see inset in Fig. S13b) with 

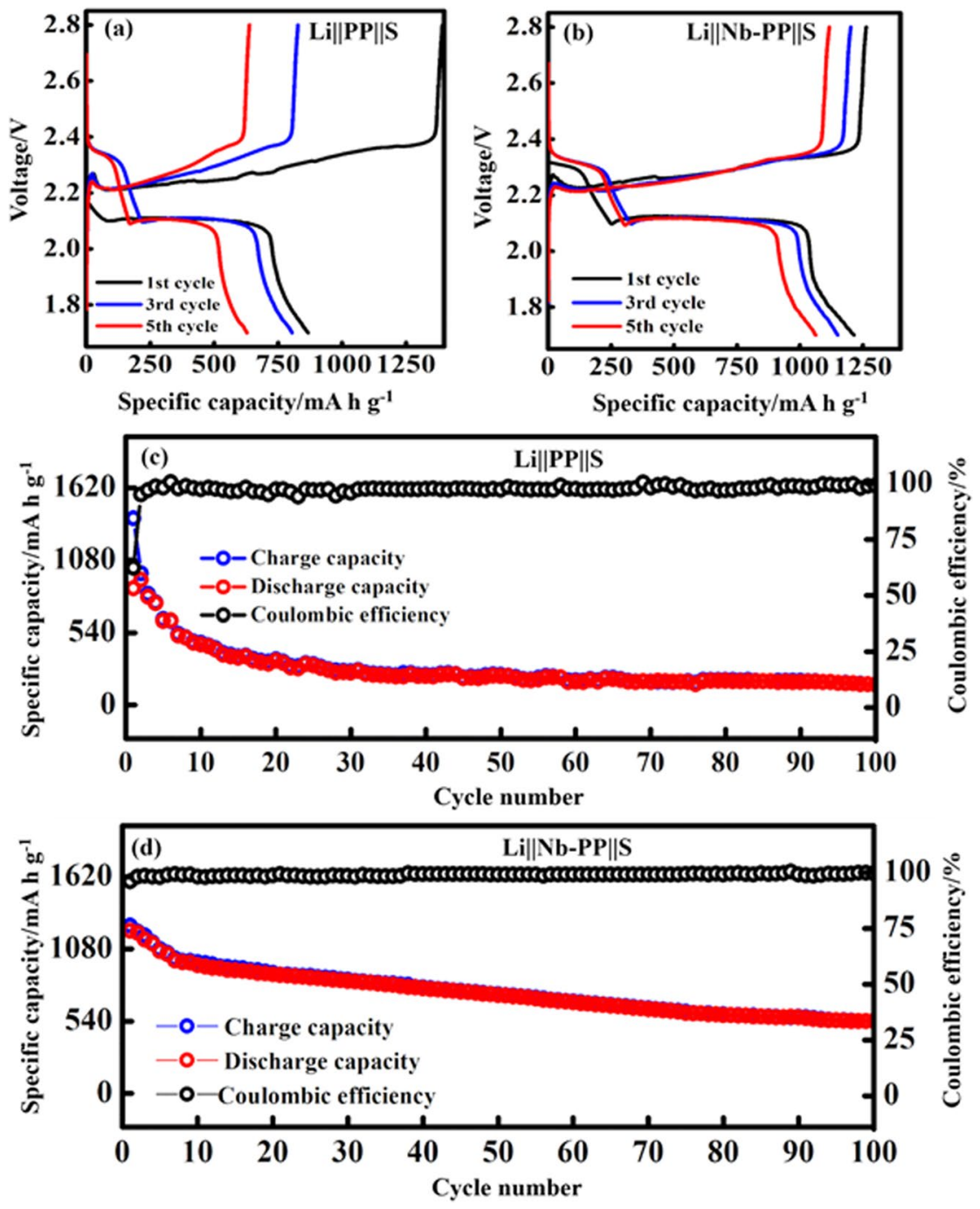

Figure 8. (a) Voltage profiles of Li-S cell with PP separator. (b) Voltage profiles of Li-S cell with Nb-PP separator. (c) Charge-discharge capacity and Coulombic efficiency of PP separator showing fast capacity decay. (d) Charge-discharge capacity and Coulombic efficiency of Nb-PP separator showing improved capacity retention.

relatively similar area under the curves, indicating better stability and cycling reversibility. To further demonstrate the electrochemical stability galvanostatic cell cycling in $1.7 \mathrm{~V}$ to $2.8 \mathrm{~V}$ voltage range at room temperature $\left(25^{\circ} \mathrm{C}\right)$ was performed for Li-S cells containing PP and Nb-PP separator. Figure 8(a,b) represents the voltage profiles of Li-S cell constructed with PP and Nb-PP separators. The Li-S cell PP separator delivered the first discharge capacity of $867 \mathrm{~mA} \mathrm{~h} \mathrm{~g}^{-1}$ and a charge capacity of $1393 \mathrm{~mA} \mathrm{~h} \mathrm{~g}^{-1}$ at $0.1 \mathrm{C}\left(1 \mathrm{C}=1672 \mathrm{mAh} \mathrm{g}^{-1}\right)$. A low discharge capacity of just $151 \mathrm{~mA} \mathrm{~h} \mathrm{~g}^{-1}$ after $100^{\text {th }}$ discharge cycle was retained by the Li-S cell with PP separator. The fast capacity fade could be associated with the highly porous structure of PP separator which is permeable to Li polysulfides and the Li dendrites ${ }^{71,72}$. It is worth mentioning that the extended voltage profile is observed during initial charging cycle in Li-S cell with pristine PP separator triggering longer charge times before attaining the upper cut off voltage, which could possibly be associated either with the Li polysulfide shuttling phenomenon during charging process ${ }^{73}$ or with the lower open circuit voltage of the cell ${ }^{74}$ (lower discharge capacity was observed for the initial cycle). In contrast, the Li-S cell with Nb-PP separator delivered a first discharge capacity of $1214 \mathrm{~mA} \mathrm{~h}$ $\mathrm{g}^{-1}$ and a charge capacity of $1264 \mathrm{~mA} \mathrm{~h} \mathrm{~g}^{-1}$ at $0.1 \mathrm{C}$ with no extending voltage profile, indicating better stability due to Li dendrite prevention and possibly the polysulfides anchoring effect of Nb-PP separator. The above results are in well agreement with the CV data presented in Fig. S13. An improved discharge capacity of above $540 \mathrm{~mA} \mathrm{~h}$ $\mathrm{g}^{-1}$ after $100^{\text {th }}$ discharge cycle was retained by the Li-S cell containing Nb-PP separator. The specific capacities and the corresponding Coulombic efficiency for the respective cells with cycle number are displayed in Fig. 8(c,d). It is clear that the Li-S constructed with PP separator displayed a sharp decrease in the capacity in the initial cycles and finally attaining a lower values of stable specific capacity after 100 cycles with an overall efficiency of less than 97\%. The huge capacity fade in conventional Li-S cell may be ascribed to the diffusion of Li polysulfides through porous PP separator, leading to the active material loss and the inimical reactions taking place at the Li anode 
resulting in corrosion of $\mathrm{Li}$ metal and the electrolyte exhaustion ${ }^{71}$. The Li-S cell containing Nb-PP separator exhibited a relatively stable cyclic behaviour and good capacity retention after 100 galvanostatic cycles with nearly $100 \%$ cycling efficiency. EIS measurements of the fabricated Li-LMNC and Li-S cells were performed to further confirm the effect of $\mathrm{Nb}$ layer on the $\mathrm{Li}^{+}$diffusion kinetics (Fig. S14a,b). The as-assembled Li-LNMC and Li-S cells with pristine PP separator exhibited high interface resistances of $534 \Omega$ and $255 \Omega$, respectively, which could be associated with the poor contact at the electrode interface ${ }^{75,76}$. In contrast, the as-assembled Li-LNMC and Li-S cells with Nb-PP separator displayed relatively lower values of interface resistances of $202 \Omega$ and $67.95 \Omega$, respectively. The lower resistance in the latter case is the outcome of improve contact at the anode electrolyte interface because of $\mathrm{Nb}$ nanolayer, which could allow the fast $\mathrm{Li}^{+}$diffusion and reduce the charge transfer resistance. These results are consistent with the $\mathrm{CV}$ and galvanostatic charge-discharge cycling measurements, where Nb-PP based cell exhibited higher performances.

\section{Conclusion}

We report binder-free $\mathrm{Nb}$ metal nanolayer coated PP separator via RF magnetron sputtering for high capacity Li metal batteries. The $\mathrm{Nb}$ metal nanolayer modified $\mathrm{PP}$ separator exhibited improved hydrophilic character which in turn resulted in its improved wettability with liquid electrolyte. Li symmetric cells constructed with $\mathrm{Nb}$ metal nanolayer deposited PP separator exhibited stable voltage profiles and delivered improved cycling performances at various current densities. The improved electrochemical characteristics of $\mathrm{Nb}-\mathrm{PP}$ separator could be ascribed to the electrical properties of $\mathrm{Nb}$ nanolayer whilst its interaction with metallic Li allow bi-directional growth of lithium to prevent the Li dendrite penetration through PP separator. The $\mathrm{Nb}$ and Li metal interactions at the interface of the cell resulted in uniform stripping and deposition of Li which in turn promote the homogeneous current distribution. The half-cells of LNMC and sulfur cathodes constructed with modified PP separator delivered an improved electrochemical cycling performances at room temperature. The $\mathrm{Nb}$ coating on PP separator greatly improves the battery safety by supressing the Li dendrite penetration. This study could pave the way for design and construction of multifunctional separators for high capacity and safe battery operations.

\section{Materials and Methods}

Commercially available Polypropylene separator (Celgard 2325, $25 \mu \mathrm{m}$ thickness), niobium (Nb) metal target (99.995\% purity and 2"diameter), Ar gas (99.99\% purity), and $\mathrm{LiNi}_{0.33} \mathrm{Mn}_{0.33} \mathrm{Co}_{0.33} \mathrm{O}_{2}$ (LNMC, Sigma Aldrich), sulfur powder (99.99\%, Alfa Aesar), lithium metal (99.99\%, Alfa Aesar), LiPF 6 in DMC (Alfa Aesar), LiTFSI (99.9\%, Sigma Aldrich), DME (99.5\%, Sigma Aldrich), DOL (99\%, Sigma Aldrich), $\mathrm{LiNO}_{3}$ (99.99\%, Sigma Aldrich) were purchased and used without further purification unless specified.

Preparation of $\mathrm{Nb}$ coated polypropylene separator. Niobium metal coating on to the polypropylene (PP) separator was performed at room temperature $\left(25^{\circ} \mathrm{C}\right)$ using radio frequency $(\mathrm{RF})$ magnetron sputtering technique. PP separator (Celgard 2325) sheet of $3 \times 3 \mathrm{~cm}$ size was carefully cleaned with ethanol and dried in vacuum overnight. After drying the PP separator was placed into the sputtering chamber (APT Global India). Niobium (Nb) metal ( 99.995 purity) disc of $2^{\prime \prime}$ diameter was used as a coating target. The distance of $25 \mathrm{~cm}$ was fixed between the target and substrate to avoid any physical damage to PP separator during the deposition processes. High purity (99.995\%) argon (Ar) gas was utilized as a carrier gas to achieve the Nb deposition. A high vacuum of $5 \times 10^{-6} \mathrm{mbar}$ was generated and a chamber pressure was maintained at $5 \times 10^{-3}$ mbar. Initially the RF power of $30 \mathrm{~W}$ was applied for $30 \mathrm{~min}$ to eliminate any possible contamination from the $\mathrm{Nb}$ target surface. Later the RF power of $25 \mathrm{~W}$ was supplied to achieve the $\mathrm{Nb}$ deposition under Ar flow at low pressure and a controlled Ar gas flow rate of $20 \mathrm{~cm}^{3} / \mathrm{min}$ using a pneumatic mass flow control integrated with the RF system. The total deposition time was $15 \mathrm{~min}$. Deposition of $\mathrm{Nb}$ on PP separator was also carried out for $30 \mathrm{~min}$ and $60 \mathrm{~min}$ of time for comparison. After completing the deposition process the coated PP separator was transferred to glove box to avoid any surface contamination.

Preparation of LNMC cathode and sulfur cathode. For the preparation of LNMC cathode, a composition of ternary LNMC materials $\mathrm{LiNi}_{0.33} \mathrm{Co}_{0.33} \mathrm{Mn}_{0.33} \mathrm{O}_{2}$ : Poly (vinylidene fluoride) (PVDF) dissolved in 2, 2-N-methyl-pyrolidinone (NMP): acetylene black $(\mathrm{AB})$ in 8:1:1 weight ratio was finely blended to form a slurry. The slurry was uniformly spread onto the aluminium tape using doctor blade. The coated aluminium tape was transferred to vacuum oven and heated at $120^{\circ} \mathrm{C}$ for $24 \mathrm{~h}$. After drying the tape was punched into small discs and transferred to Ar-filled glove box for cell assembling.

The elemental sulfur and active carbon in a weight ratio of 1:1 were hand mixed in agate motor and later placed in a sealed glass bottle under Ar atmosphere. The glass bottle was heat treated in vacuum at $155^{\circ} \mathrm{C}$ for $15 \mathrm{~h}$ and later slowly cooled down to room temperature to obtain the carbon-sulfur composite.

For the composite cathode preparation the carbon-sulfur composite was mixed with PVDF dissolved in NMP and $\mathrm{AB}$ in a weight ratio of $8: 1: 1$ to obtain a slurry. The slurry was blade coated on to the $\mathrm{Al}$ tape. The coated $\mathrm{Al}$ tape was vacuum dried at $60^{\circ} \mathrm{C}$ before shifting to the glove box for cell assembling.

Materials characterization. Scanning electron microscopy (SEM) was utilized to view the microstructure and cross-section of PP separator, Nb-PP separator, pristine and cycled Li metal surface. To avoid any possible effect of coating layers, $\mathrm{Li}$ and $\mathrm{Nb}-\mathrm{PP}$ samples were sputter coated without any additional carbon (C) or gold (Au). Energy X-ray dispersive spectroscopy (EDS) analysis of Nb coated PP separator was carried out for elemental analysis. Contact angle measurements were performed on the $\mathrm{Nb}-\mathrm{PP}$ separator with water and liquid electrolyte to analyse the wettability of the modified separator. Differential scanning calorimetry was performed to investigate the thermal stability of Nb-PP separator. 
Electrolyte preparation, cell assembling and electrochemical characterization. Ether based organic liquid electrolyte containing $1.0 \mathrm{ML}^{-1}$ lithium bis(trifluoromethane) sulphonimide (1.0 $\mathrm{ML}^{-1}$ LiTFSI) in mixed solvents of 1,2-dimethoxyethane (DME) and 1,3-dioxolane (DOL) $(\mathrm{V} / \mathrm{V}=1: 1)$ was prepared inside Ar-filled glove box. Briefly, the stoichiometric amount of LiTFSI salt was first dried at $100^{\circ} \mathrm{C}$ inside glove box. After drying, it was weighted for $1.0 \mathrm{M} \mathrm{L}^{-1}$ and transferred into a sealed glass bottle. DME and DOL solvents were then added in equal volume ratios (1:1 volume ratio) to LiTFSI salt to prepare the electrolyte solution. The LiTFSI salt was dissolved in solvents under continuous magnetic stirring for $24 \mathrm{~h}$. Cell assembling was performed inside Ar-filled glove box $\left(\mathrm{H}_{2} \mathrm{O}\right.$ and $\mathrm{O}_{2} \leq 0.5$ ppm). Symmetric cells of Li||PP@PP||Li and Li || $\mathrm{Nb}-\mathrm{PP} @ \mathrm{PP}-\mathrm{Nb}|| \mathrm{Li}$ configuration with Li metal discs of area $0.5 \mathrm{~cm}^{2}$ and two PP separators/Nb-PP separators (hereafter PP@PP/ $\mathrm{Nb}-\mathrm{PP} @ \mathrm{PP}-\mathrm{Nb}$ ) of area $1.13 \mathrm{~cm}^{2}$ sandwiched together with $\mathrm{Nb}$ coated side facing towards lithium metal in the later configuration were fabricated inside glove box. $30 \mu \mathrm{L}$ of $1.0 \mathrm{M} \mathrm{L}^{-1} \mathrm{LiTFSI}$ in DME: DOL was used as liquid electrolyte in each symmetric cell.

LNMC cathode based cells were fabricated in CR 2032 configuration containing a LNMC cathode disc $(2.5$ $\mathrm{mg}_{\mathrm{LNMC}} \mathrm{cm}^{-2}$ ) of area $0.785 \mathrm{~cm}^{2}$, well cleaned Li disc of area $1.13 \mathrm{~cm}^{2}$ as reference and counter electrode, $2 \mathrm{Nb}-$ $\mathrm{PP}$ separator with $\mathrm{Nb}$ coated side facing towards $\mathrm{Li}$ and $25 \mu \mathrm{L}$ of $1.0 \mathrm{ML}^{-1}$ lithium hexafluorophosphate $\left(\mathrm{LiPF}_{6}\right)$ dissolved in dimethyl carbonate (DMC) as a liquid electrolyte. Composite sulfur cathode based cells were fabricated in CR 2032 configuration containing a sulfur cathode disc $\left(2.0 \mathrm{mg}_{\text {sulfur }} \mathrm{cm}^{-2}\right)$ of area $0.785 \mathrm{~cm}^{2}$, Li disc of area $1.13 \mathrm{~cm}^{2}, \mathrm{Nb}$-PP separator with $\mathrm{Nb}$ coated side facing towards $\mathrm{Li}$ and $25 \mu \mathrm{L}$ of $1.0 \mathrm{ML}^{-1}$ LiTFSI containing $0.1 \mathrm{ML}^{-1} \mathrm{LiNO}_{3}$ in DME and DOL (V/V $\left.=1: 1\right)$. The assembled cells were aged for $24 \mathrm{~h}$ before the electrochemical measurements. All electrochemical measurements were performed under room temperature conditions $\left(25^{\circ} \mathrm{C}\right)$. Electrochemical impedance spectroscopy (EIS) tests and cyclic voltammetry (CV) were carried out in Bio Logic VSP-300 workstation. Cell cycling measurements were performed in Bio Logic VSP-300 and Arbin battery testers.

Received: 10 July 2019; Accepted: 11 October 2019;

Published online: 14 November 2019

\section{References}

1. Antolini, E. $\mathrm{LiCoO}_{2}$ : formation, structure, lithium and oxygen nonstoichiometry, electrochemical behaviour and transport properties. Solid State Ionics 170, 159-171 (2004).

2. Wang, J. \& Sun, X. Olivine $\mathrm{LiFePO}_{4}$ : the remaining challenges for future energy storage. Energy Environ. Sci. 8, 1110-1138 (2015).

3. Yuan, L. X. et al. Energy Environ. Sci. 4, 269-284 (2011).

4. Koksbang, R., Barker, J., Shi, H. \& Saidi, M. Y. Cathode materials for lithium rocking chair batteries. Solid state ionics 84, 1-21 (1996).

5. Whittingham, M. S. Lithium batteries and cathode materials. Chem. Rev. 104, 4271-4302 (2004).

6. Luo, W., Li, X. \& Dahn, J. R. Synthesis, characterization, and thermal stability of $\mathrm{Li}_{[}\left[\mathrm{Ni}_{1 / 3} \mathrm{Mn}_{1 / 3} \mathrm{Co}_{1 / 3-\mathrm{z}}(\mathrm{MnMg})_{\mathrm{z} / 2}\right] \mathrm{O}_{2}$. Chem. Mater. 22, 5065-5073 (2010).

7. Winter, M., Besenhard, J. O., Spahr, M. E. \& Novak, P. Insertion electrode materials for rechargeable lithium batteries. Adv. mater. 10, 725-763 (1998)

8. Tarascon, J.-M. \& Armand, M. Issues and challenges facing rechargeable lithium batteries. Nature 414, 359-367 (2001).

9. Cahill, L. S. et al. ${ }^{6} \mathrm{Li}$ NMR studies of cation disorder and transition metal ordering in $\mathrm{Li}\left[\mathrm{Ni}_{1 / 3} \mathrm{Mn}_{1 / 3} \mathrm{Co}_{1 / 3}\right] \mathrm{O}_{2}$ using ultrafast magic angle spinning. Chem. Mater. 17, 6560-6566 (2005).

10. Guler, A. et al. A high-performance composite positive electrode based on graphene and $\mathrm{Li}\left(\mathrm{Ni}_{1 / 3} \mathrm{Co}_{1 / 3} \mathrm{Mn}_{1 / 3}\right) \mathrm{O}_{2}$. Int. J. Energy Res. 42, 4499-4511 (2018).

11. He, P., Wang, H., Qi, L. \& Osaka, T. Electrochemical characteristics of layered $\mathrm{LiNi}_{1 / 3} \mathrm{Co}_{1 / 3} \mathrm{Mn}_{1 / 3} \mathrm{O}_{2}$ and with different synthesis conditions. J. Power Sources 160, 627-632 (2006).

12. Cho, T. H., Park, S. M., Yoshio, M., Hirai, T. \& Hideshima, Y. Effect of synthesis condition on the structural and electrochemical properties of $\mathrm{Li}\left[\mathrm{Ni}_{1 / 3} \mathrm{Mn}_{1 / 3} \mathrm{Co}_{1 / 3}\right] \mathrm{O}_{2}$ prepared by carbonate coprecipitation method. J. Power Sources 142, 306-312 (2005).

13. Shaju, K. M., Subba Rao, G. V. \& Chowdari, B. V. R. Performance of layered $\mathrm{Li}\left(\mathrm{Ni}_{1 / 3} \mathrm{Co}_{1 / 3} \mathrm{Mn}_{1 / 3}\right) \mathrm{O}_{2}$ as cathode for Li-ion batteries. Electrochim. Acta 48, 145-151 (2002).

14. Guo, J. et al. Effect of synthesis condition on the structural and electrochemical properties of $\operatorname{Li}\left[\mathrm{Ni}_{1 / 3} \mathrm{Mn}_{1 / 3} \mathrm{Co}_{1 / 3}\right] \mathrm{O}_{2}$ prepared by the metal acetates decomposition method. Electrochim. Acta 51, 3731-3735 (2006).

15. Ren, H. et al. Synthesis of $\mathrm{LiNi}_{1 / 3} \mathrm{Co}_{1 / 3} \mathrm{Mn}_{1 / 3} \mathrm{O}_{2}$ as a cathode material for lithium battery by the rheological phase method. J. Power Sources 178, 439-444 (2008).

16. Wang, Y., Roller, J. \& Maric, R. Morphology-controlled one-step synthesis of nanostructured $\mathrm{LiNi}_{1 / 3} \mathrm{Mn}_{1 / 3} \mathrm{Co}_{1 / 3} \mathrm{O}_{2}$ electrodes for Li-ion batteries. ACS Omega 3, 3966-3973 (2018).

17. Rauh, R. D., Abraham, K. M., Pearson, G. F., Surprenant, J. K. \& Brummer, S. B. A lithium/dissolved sulfur battery with an organic electrolyte. J. Electrochem. Soc. 126, 523-527 (1979).

18. Cheon, S. E. et al. Rechargeable lithium sulfur battery: I. Structural change of sulfur cathode during discharge and charge. J. Electrochem. Soc. 150, 796-799 (2003).

19. Yang, Y. et al. High-capacity micrometer-sized $\mathrm{Li}_{2} \mathrm{~S}$ particles as cathode materials for advanced rechargeable lithium-ion batteries. J. Am. Chem. Soc. 134, 15387-15394 (2012).

20. Manthiram, A., Fu, Y., Chung, S. H., Zu, C. \& Su, Y. S. Rechargeable lithium-sulfur batteries. Chem. Rev. 114, 11751-11787 (2014).

21. Zhang, S., Ueno, K., Dokko, K. \& Watanabe, M. Recent advances in electrolytes for lithium-sulfur batteries. Adv. Energy Mater. 5, 1500117 (2015).

22. Chung, S. H. \& Manthiram, A. Current Status and Future Prospects of Metal-Sulfur Batteries. Adv. Mater. 31, 1901125 (2019).

23. Hu, G. et al. 3d graphene-foam-reduced-graphene-oxide hybrid nested hierarchical networks for high-performance Li-S batteries. Adv. Mater. 28, 603-1609 (2016).

24. Yuan, Z. et al. Hierarchical free-standing carbon-nanotube paper electrodes with ultrahigh sulphur-loading for lithium-sulphur batteries. Adv. Funct. Mater. 24, 6105-6112 (2014).

25. Zhou, G. et al. A graphene foam electrode with high sulphur loading for flexible and high energy Li-S batteries. Nano Energy 11, 356-65 (2015).

26. Qie, L. \& Manthiram, A. A facile layer-by-layer approach for high-areal-capacity sulphur cathodes. Adv Mater. 27, 1694-1700 (2015).

27. Lu, S., Chen, Y., Wu, X., Wang, Z. \& Li, Y. Three-dimensional sulphur/graphene multifunctional hybrid sponges for lithium-sulphur batteries with large areal mass loading. Sci. Reports. 4, 4629 (2014).

28. Li, Z. et al. electrode design for high-energy density lithium-sulphur batteries. Nat Commun. 6, 8850 (2015). 
29. Cheng, X. B. et al. Aligned carbon nanotube/sulphur composite cathodes with high sulphur content for lithium-sulphur batteries. Nano Energy 4, 65-72 (2014).

30. Miao, L., Wang., W., Yuan, K., Yang, Y. \& Wang, A. A lithium sulphur cathode with high sulphur loading and high capacity per area: a binder-free carbon fiber cloth-sulphur material. Chem. Commun. 50, 13231-13234 (2014).

31. Du, W. C. et al. Wet chemistry synthesis of multidimensional nanocarbon-sulphur hybrid materials with ultrahigh sulphur loading for lithium-sulphur batteries. ACS Appl. Mater. Interfaces 8, 3584-3590 (2016).

32. Fang, R. et al. 3D interconnected electrode materials with ultrahigh areal sulphur loading for Li-S batteries. Adv. Mater. 28, 3374-3382 (2016).

33. Wei, S., Ma, L., Hendrickson, K. E., Tu, Z. \& Archer, L. A. Metal-sulphur battery cathodes based on PAN-sulphur composites. J. Am. Chem. Soc. 137, 12143-12152 (2015).

34. Chen, J. J. et al. Conductive Lewis base matrix to recover the missing link of $\mathrm{Li}_{2} \mathrm{~S}_{8}$ during the sulphur redox cycle in Li-S battery. Chem. Mater. 27, 2048-2055 (2015).

35. Xu, G. et al. Sulfur embedded in metal organic framework-derived hierarchically porous carbon nanoplates for high performance lithium-sulfur battery. J. Mater. Chem. A 1, 4490-4496 (2013).

36. Li, N. et al. High-rate lithium-sulfur batteries promoted by reduced graphene oxide coating. Chem. Commun. 48, 4106-4108 (2012).

37. Huang, J. Q. et al. Ionic shield for polysulfides towards highly-stable lithium-sulfur batteries. Energy Environ. Sci. 7, 347-353 (2014).

38. Wang, B., Alhassan, S. M. \& Pantelides, S. T. Formation of large polysulfide complexes during the lithium-sulfur battery discharge. Phys. Rev. App. 2, 034004 (2014).

39. She, Z. W. et al. Sulphur-TiO ${ }_{2}$ yolk-shell nanoarchitecture with internal void space for long-cycle lithium-sulphur batteries. Nat. commun. 4, 1331 (2013).

40. Xu, W. et al. Lithium metal anodes for rechargeable batteries. Energy Environ. Sci. 7, 513-537 (2014).

41. Li, W. et al. The synergetic effect of lithium polysulfide and lithium nitrate to prevent lithium dendrite growth. Nat. commun. 6, 7436 (2015).

42. Cheng, X. B., Zhang, R., Zhao, C. Z. \& Zhang, Q. Toward safe lithium metal anode in rechargeable batteries: a review. Chem. Rev. 117, 10403-10473 (2017).

43. Bhattacharyya, R. et al. In situ NMR observation of the formation of metallic lithium microstructures in lithium batteries. Nat. Mater. 9, 504 (2010).

44. Suo, L., Hu, Y. S., Li, H., Armand, M. \& Chen, L. A new class of solvent-in-salt electrolyte for high-energy rechargeable metallic lithium batteries. Nat. commun. 4, 1481 (2013).

45. Chandrashekar, S. et al. ${ }^{7} \mathrm{Li}$ MRI of Li batteries reveals location of microstructural lithium. Nat. Mater. 11, 311-315 (2012).

46. Chen, Y., Dou, X., Wang, K. \& Han, Y. Lithium dendrites inhibition via diffusion enhancement. Adv. Energy Mater. 9, 1900019 (2019).

47. Wood, K. N. et al. Dendrites and pits: untangling the complex behavior of lithium metal anodes through operando video microscopy. ACS Cent. Sci. 2, 790-801 (2016).

48. Aurbach, D., Zinigrad, E., Teller, H. \& Dan, P. Factors which limit the cycle life of rechargeable lithium (metal) batteries. J. Electrochem. Soc. 147, 1274-1279 (2000).

49. Dornbusch, D. A., Hilton, R., Lohman, S. D. \& Suppes, G. J. Experimental validation of the elimination of dendrite short-circuit failure in secondary lithium-metal convection cell batteries. J. Electrochem. Soc. 162, 262-268 (2015).

50. Rana, M. et al. Recent advances in separators to mitigate technical challenges associated with re-chargeable lithium sulfur batteries. J. Mater. Chem. A 7, 6596-6615 (2019).

51. Li, G. C. et al. A hydrophilic separator for high performance lithium sulfur batteries. J. Mater. Chem. A 3, 11014-11020 (2015).

52. Zhang, Z., Lai, Y., Zhang, Z., Zhang, K. \& Li, J. $\mathrm{Al}_{2} \mathrm{O}_{3}$-coated porous separator for enhanced electrochemical performance of lithium sulfur batteries. Electrochim. Acta 129, 55-61 (2014).

53. Li, J. et al. Decoration of silica nanoparticles on polypropylene separator for lithium-sulfur batteries. ACS appl. Mater. Interfaces 9 , 7499-7504 (2017).

54. Din, M. M. U., Sahu, B. K., Das, A. \& Murugan, R. Enhanced electrochemical performance of lithium-sulphur battery by negating polysulphide shuttling and interfacial resistance through aluminium nanolayer deposition on a polypropylene separator. Ionics $\mathbf{2 5}$, 1645-1657 (2019).

55. Tang, Q., Li, H., Pan, Y., Zhang, J. \& Chen, Y. Protecting lithium metal anode by magnetron sputtering a copper coating. Ionics 25 , 2525-2533 (2019).

56. Lee, H. et al. Suppressing lithium dendrite growth by metallic coating on a separator. Adv. Funct. Mater. 27, 1704391 (2017).

57. Lee, T., Kim, W. K., Lee, Y., Ryou, M. H. \& Yong, M. L. Effect of $\mathrm{Al}_{2} \mathrm{O}_{3}$ coatings prepared by RF sputtering on polyethylene separators for high-power lithium ion batteries. Macromol. Res. 22, 1190-1195 (2014).

58. Wen, K., Liu, L., Chen, S. \& Zhang, S. A bidirectional growth mechanism for a stable lithium anode by a platinum nanolayer sputtered on a polypropylene separator. RSC Adv. 8, 3034-13039 (2018).

59. Peng, K., Wang, B., Li, Y. \& Ji, C. Magnetron sputtering deposition of $\mathrm{TiO}_{2}$ particles on polypropylene separators for lithium-ion batteries. RSC Adv. 5, 81468-81473 (2015).

60. Shu, Q. A Pt decorated polypropylene separator for high performance Li-S battery. Mater. Res. Express 6, 055508 (2019).

61. Chung, S. Y., Bloking, J. T. \& Chiang, Y. M. Electronically conductive phospho-olivines as lithium storage electrodes. Nat. mater. 1, 123 (2002).

62. Tao, Y. et al. Kinetically-enhanced polysulfide redox reactions by $\mathrm{Nb}_{2} \mathrm{O}_{5}$ nanocrystals for high-rate lithium-sulfur battery. Energy Environ. Sci. 9, 3230-3239 (2016).

63. Wen, X. et al. $\mathrm{Nb}_{2} \mathrm{O}_{5}$-Decorated Nitrogen-Doped Carbon Nanotube Microspheres for Highly Efficient Sulfur Confinement in Lithium-Sulfur. Batteries. Ind. Engg. Chem. Res. 58, 8724-8733 (2019).

64. Wang, T., Salvatierra, R. V. \& Tour, J. M. Detecting Li Dendrites in a Two-Electrode Battery System. Adv. Mater. 31, 1807405 (2019).

65. Li, X. et al. \& Sun. Atomic layer deposition of solid-state electrolyte coated cathode materials with superior high-voltage cycling behavior for lithium ion battery application. Energy Environ. Sci. 7, 768-778 (2014).

66. Wu, F. et al. Sulfur/polythiophene with a core/shell structure: synthesis and electrochemical properties of the cathode for rechargeable lithium batteries. J. Phys. Chem. C 115, 6057-6063 (2011).

67. Oh, C. et al. Enhanced Li-S battery performance based on solution-impregnation-assisted sulfur/mesoporous carbon cathodes and a carbon-coated separator. J. Mater. Chem. A 5, 5750-5760 (2017).

68. Yuan, Z. et al. 2016. Powering lithium-sulfur battery performance by propelling polysulfide redox at sulfiphilic hosts. Nano Lett. 16, 519-527 (2016).

69. Stoeck, U. et al. Reconfiguration of lithium sulfur batteries: Enhancement of Li-S cell performance by employing a highly porous conductive separator coating. J. Power Sources 309, 76-81 (2016).

70. Li, L. et al. Molecular understanding of polyelectrolyte binders that actively regulate ion transport in sulfur cathodes. Nat. commun. 8, 2277 (2017).

71. Li, H., Tang, W., Huang, Y., Ruan, W. \& Zhang, M. Nanopore separator of cross-linked poly (propylene glycol)-co-pentaerythritol triacrylate for effectively suppressing polysulfide shuttling in Li-S batteries. Polymer Chem. 10, 2697-2705 (2019).

72. Saravanan, K., Kalimuthu, B., Mohammed, A. N., Krishnamurty, S. \& Nallathamby, K. Effective polysulfides trapping polar interlayer for high rate Li-S. batteries. J. Mater. Chem. A 7, 10067-10076 (2019). 
73. Ding, N. et al. Building better lithium-sulfur batteries: from $\mathrm{LiNO}_{3}$ to solid oxide catalyst. Sci. reports 6, 33154 (2016).

74. Huang, S. et al. Mechanism investigation of high-performance Li-polysulfide batteries enabled by tungsten disulfide nanopetals. ACS nano 12, 9504-9512 (2018).

75. Al Salem, H., Babu, G., V. Rao, C. \& Arava, L. M. R. Electrocatalytic polysulfide traps for controlling redox shuttle process of Li-S batteries. J. Am. Chem. Soc. 137, 11542-11545 (2015).

76. Su, Y. -S. \& Manthiram, A. Lithium-sulfur batteries with a microporous carbon paper as a bifunctional interlayer. Nat. Commun. 3, 1166 (2012).

\section{Acknowledgements}

R.M. acknowledges the SERB, Govt. of India for support (EMR/2017/000417). M.M.U. Din gratefully acknowledges the fellowship support from UGC-MANF, Govt. of India.

\section{Author contributions}

R.M. conceived and supervised the research work. M.M.U. Din performed the experimental work/ characterization, electrochemical measurements and wrote the manuscript. All authors reviewed the manuscript.

\section{Competing interests}

The authors declare no competing interests.

\section{Additional information}

Supplementary information is available for this paper at https://doi.org/10.1038/s41598-019-53257-4.

Correspondence and requests for materials should be addressed to R.M.

Reprints and permissions information is available at www.nature.com/reprints.

Publisher's note Springer Nature remains neutral with regard to jurisdictional claims in published maps and institutional affiliations.

(c) (i) Open Access This article is licensed under a Creative Commons Attribution 4.0 International License, which permits use, sharing, adaptation, distribution and reproduction in any medium or format, as long as you give appropriate credit to the original author(s) and the source, provide a link to the Creative Commons license, and indicate if changes were made. The images or other third party material in this article are included in the article's Creative Commons license, unless indicated otherwise in a credit line to the material. If material is not included in the article's Creative Commons license and your intended use is not permitted by statutory regulation or exceeds the permitted use, you will need to obtain permission directly from the copyright holder. To view a copy of this license, visit http://creativecommons.org/licenses/by/4.0/.

(C) The Author(s) 2019 